\title{
Student Reminder Android Based System
}

\section{Anil V. Turukmane}

\begin{abstract}
Now a day's usage of android applications has become a part of our life. By using these applications our work becomes simple and easier in our day to day activities. This paper suggests an android application which is generally useful for the students and parents. It contains various features like notifying the student about the renewal date of library books, alerting students and their parents about the percentage of attendance and reminds them about number of classes they should present to maintain the specified attendance threshold. This application also alerts the students and parents about various events like examinations, workshops to be held, student activities to be conducted etc. This application is user friendly and can be installed in any android smart phone.
\end{abstract}

Keywords: Android, smart phone, reminder, Attendance Management, Alerts, library renewal.

\section{INTRODUCTION}

Now a day's smart phone usage is very wider because of the advanced mobile operating system with features suitable for mobile, handheld use. They are capable of running downloaded applications (apps) [1-4]. Smart phone apps are easy to use and are time saving applications.

Most of the popular operating systems used in smart phones are Blackberry, iOS, Windows, and Android. In this paper we choose Android application because it is an open source and free. Today more than $70 \%$ of smart phones run on android operating system. Android applications became more popular in recent years. Usage of the applications has grown up to a greater extent since they make day to day tasks and works easy. Anyone can also download, install and use the applications easily. The application now developed by us can be installed by both students and their parents. The parents can monitor the attendance of their children and instruct them to maintain the specified attendance threshold. Percentage of student attendance in the class room is one of the parameter to increase the standard of education in addition to result and quality of teaching etc. This application also alerts the students about the renewal date of the library books, so that they can renewal their books without paying the fine. The students and their parents can also view the current updates and browse the important links related to the college through this application. This paper is organized as follows, section 2 explains the literature survey. Section 3 explains our proposed work. Section 4 elucidates the experimentation results and section 5 ends with the conclusions.

\section{LITERARY SURVEY}

Several applications have been developed to monitor the attendance.

Revised Manuscript Received on February 05, 2020.

* Correspondence Author

Dr. Anil V Turukmane, Associate Professor, Sharad Institute of Technology College of Engineering, Ichalkaranji, Kolhapur, Maharashtra, India. E-mail:anilturukmane@gmail.com

(C) The Authors. Published by Blue Eyes Intelligence Engineering and Sciences Publication (BEIESP). This is an open access article under the CC BY-NC-ND license (http://creativecommons.org/licenses/by-nc-nd/4.0/)
Dhiman kumar sarkar, Nafiez Ishtaique Hossian and Insan Arafat Jamil [5] proposed an application using radio frequency identification, biometric fingerprint sensor and password based technology developed in C\# environment. This application runs only on windows operating system which is rarely used in smart phone.

Jun lio [6] proposed an attendance management framework in combination with mobile devices and web services. In this work he proposed a method where a student can choose an option, registration by selfie or registration by signature to mark the attendance but no reminder system is proposed in this technique.

Library management system as in [7] requires more time to access the information. Our application provides an easy interface that alarms on the day of renewal date and gives information about the book taken from the library.

Yu Xiang [8] compared the capability of attendance check methods like One-stop Attendance and Absent System, concurrent check, proxy attendance and preventing of movement.

A.J. Kadam, Aradhana Singh, Komal Jagtap and Srujana Tankala [9] in their work proposed an application to manage the student information in an institute. The advantage of this application is mobility, secure and less error prone.

\section{PROPOSED METHODOLOGY}

In the previous system the student has to view the information in the hard file or the web site. If his attendance fall less than the specified attendance threshold, he couldn't know it until the counselor or teacher informs him or his parent. The student to renewal the book needs to remember or to check the book for renewal date.

In this paper, we propose an android based mobile application which is useful to the students and their parents. They can know attendance status and can get alert for renewal of the book taken in the library. The student and his parent can also know the recent updates in the college and also can browse directly to the important links of the college.

\section{a. Block Diagram of System Architecture of Student reminder system}

Fig. 1 illustrates the system components of our application. Our application is a mobile application developed in Android studio using Java, back end database used is SQL and PHP. The android app is more secure because it is a multi-user Linux system which assigns each app a unique Linux user ID by default. To store the data we used the College Management System web service. 


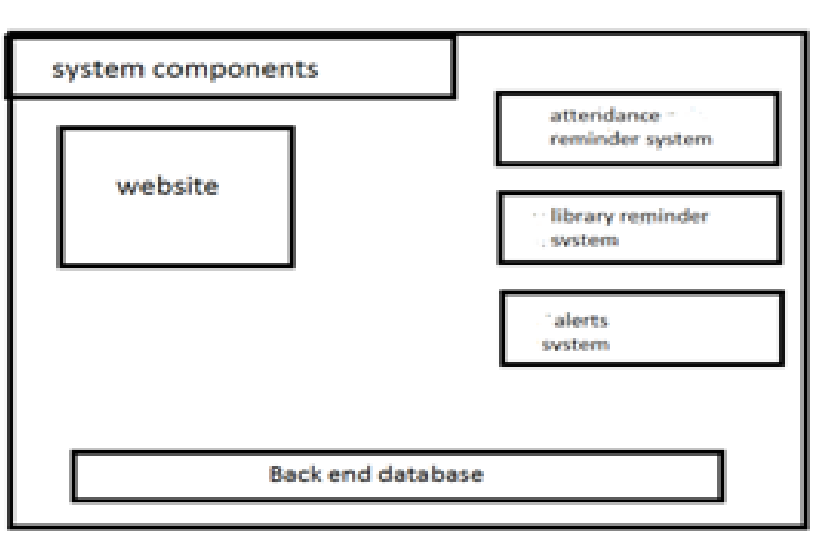

Fig. 1 Block diagram of system architecture

This application is mainly useful for the students in managing some of their daily college activities. Library reminder system is one of the features of this application. In this application the student enters the book details such as name of the book and date of the book issued. This application calculates the specified renewal date and on that date it reminds the students to renewal the book. The flow of this feature is shown as in fig. 1 . The details get stored in the database so that the student can view the details of the book he has taken from the library. The details stored in the database are name of the book, date of the book issued and the number of days after the book need to be renewal etc.

\section{b. Algorithm}

For example, suppose student enters the book details and the issue date of book as Java and March 5th 2017 then the student after 20 days i.e., on March 25th 2017 automatically gets an alarm alert indicating to renewal the book.
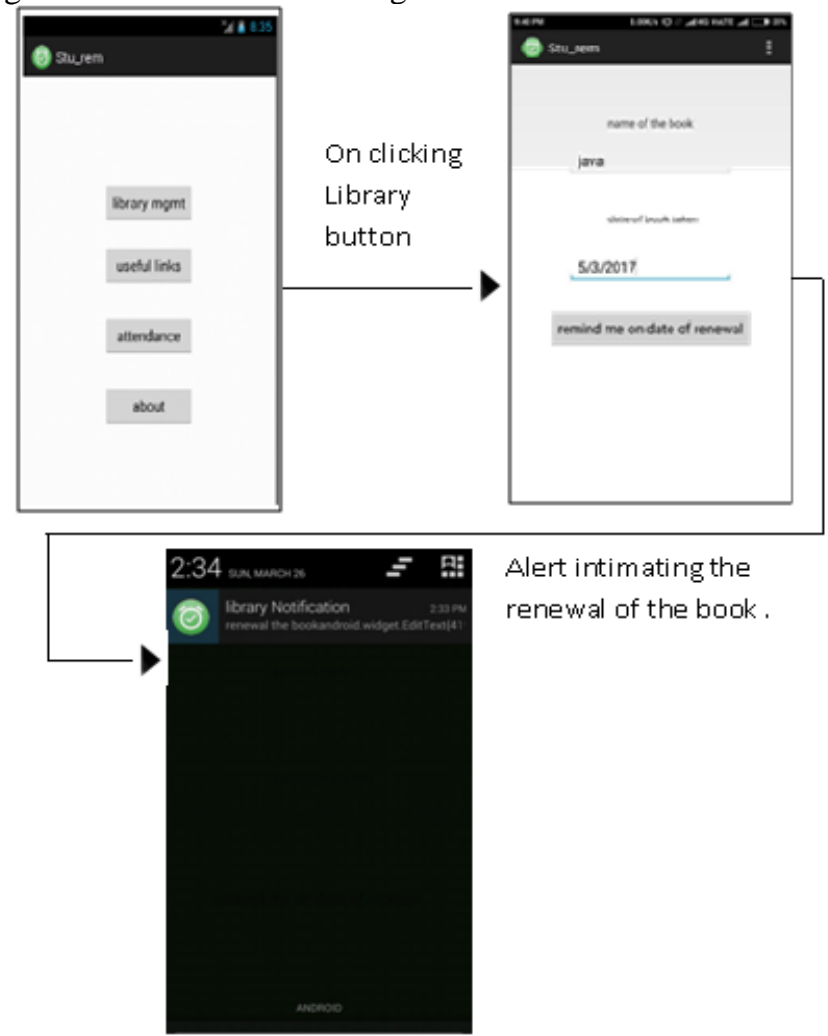

Alert intimating the renewal of the book.

Fig.2: Flow of the Library remainder system

Attendance reminder system is another feature of this application which estimates the percentage of student attendance by considering the student attendance details from the College Management System (CMS). The attendance is uploaded by the lecturer through CMS. If the attendance percentage is less than the specified attendance threshold then it notifies the student and parent about the attendance status. This is shown in fig. 2

\section{c. Flow Chart}

For example in fig.3 the specified attendance threshold is $75 \%$. As the attendance is less than this then the student and parent gets an alert that the student need to attend 5 more classes to maintain $75 \%$ attendance.

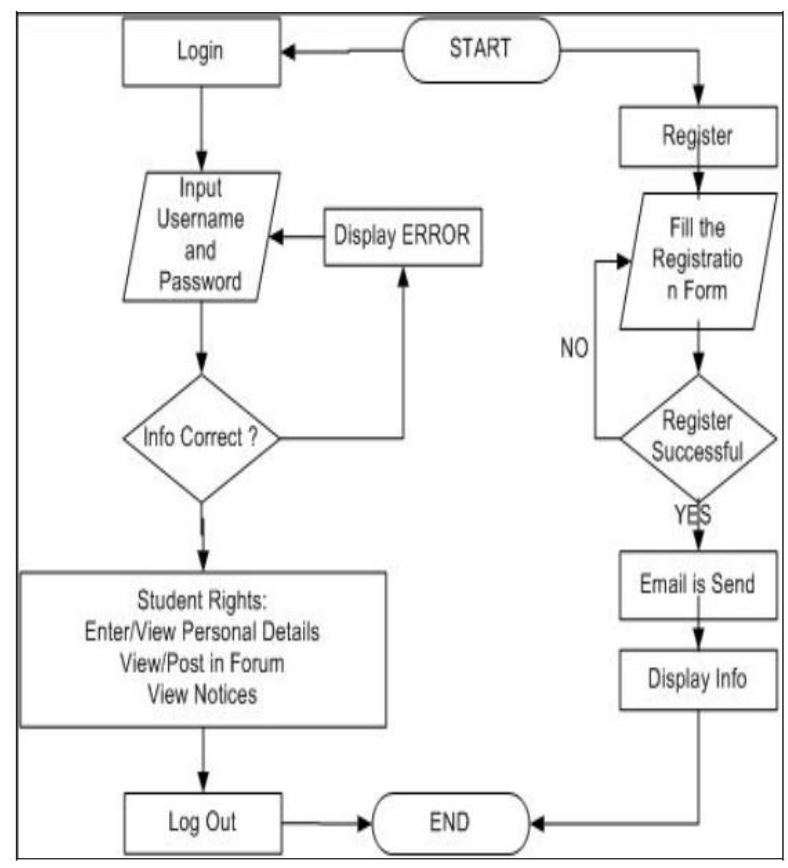

Fig. 3: Flow chart of the system.

This application also consists of a feature that alerts the students and their parents about various events like examination alerts, student activities etc., as shown in fig. 4 and the important links can be browsed as shown in fig. 5 .

\section{RESULT ANALYSIS}

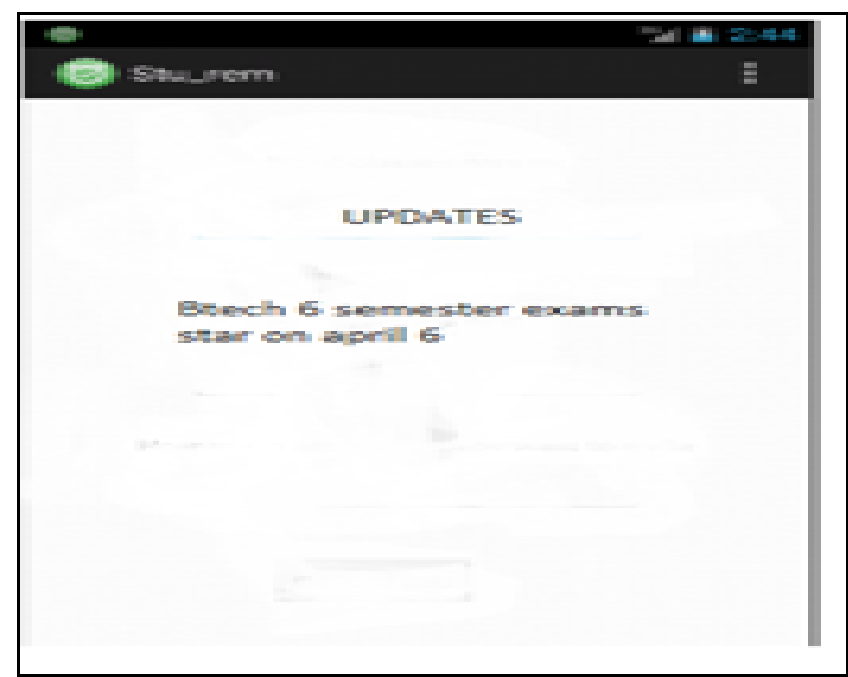

Fig. 4: Examination alert

Published By: 


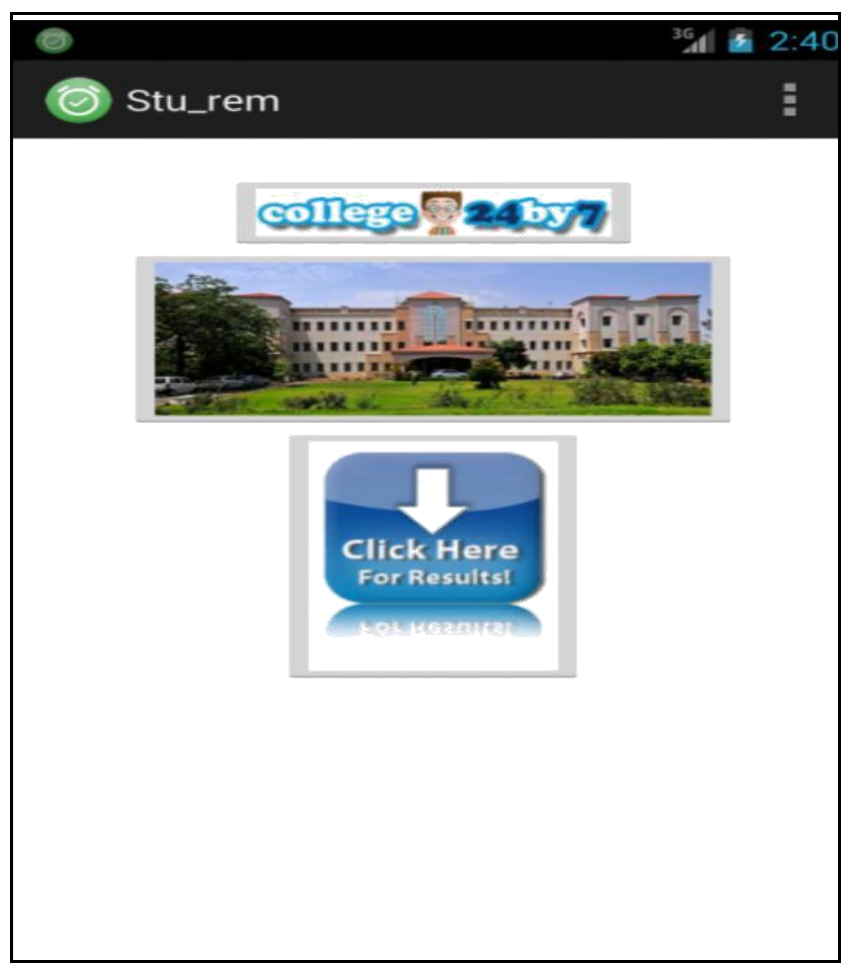

Fig. 5: Important links that can be browsed

\section{Evaluation of Student reminder system}

In our Institution, students without having $75 \%$ percentage of attendance cannot sit for an examination. Attendance is considered as a part of the continuous assessment. Every lecturer in the college uploads the attendance through College Management System (CMS). This attendance is stored in the database. No lecturer except the Head of the Department is given permission to alter the attendance. Our application acquires the attendance details of the student from this database and if he falls below 75\% attendance limit then he gets an alert.

- The proposed system is user friendly. The graphical user interfaces endowed in the proposed application provides user to deal with the system very easily.

- The proposed system requires no paper work. The user need not remember or note down the information on the paper.

- All the calculations are predefined they are programmed and installed into application so that there is no chance of error.

Table 1: Feedback result List of participants

\begin{tabular}{|l|l|l|l|l|}
\hline $\begin{array}{l}\text { N } \\
\text { o. }\end{array}$ & Profession & Age & $\begin{array}{l}\text { Gende } \\
\text { r }\end{array}$ & Feedback \\
\hline 1 & Student & 33 & Male & $\begin{array}{l}\text { It recognizes activity and } \\
\text { prompt alarm on time }\end{array}$ \\
\hline t2 & Student & 34 & Male & $\begin{array}{l}\text { It gives me the freedom of } \\
\text { pressing buttons }\end{array}$ \\
\hline 3 & Student & 29 & Male & $\begin{array}{l}\text { The interactive images } \\
\text { give me an impression not } \\
\text { to read text. }\end{array}$ \\
\hline 4 & Parent & 43 & Femal & $\begin{array}{l}\text { Sending notification to } \\
\text { another person is } \\
\text { interesting feature }\end{array}$ \\
\hline 5 & Parent & 48 & Male & $\begin{array}{l}\text { I like the automatic } \\
\text { snooze feature }\end{array}$ \\
\hline
\end{tabular}

- The technical requirement for the proposed system is economical and it does not use any other additional Hardware and software.

- User requires no special training about the operating system. Installing of the application by the user is easy by just knowing two to three steps

\section{CONCLUSION}

Student Reminder application is user friendly application which helps the student in managing daily activities of college such as attendance library management and also contain useful links required daily for academics by installing this student reminder application in ones smart phone.

Each and every student of college will install this app so that it will be helpful in renewing or returning of their library books without paying fine. In case of regular absence to college for many days this application gives an idea for how many days still he should be present to make up his required attendance. This app has many advantages to the students and their parents if they would install it. Moreover now-a-days everyone is using smart phone all that they have to do is to install the application and use it.

\section{REFERENCES}

1. Puchong Subpratatsavee, Tanabat Promjun, Wichian Siriprom, Worasitti Sriboon, Attendance System using NFC technology and embedded camera device on mobile phone. In: IEEE International Conference on Information Science and Applications, 2014.

2. Shailendra, M.Singh, M.A.Khan, V.Singh, A.Palit, S.Wadar, Attendance Management System. In: IEEE International Conference on Electronics and Communication Systems, 2015; pp. 418-422.

3. Geetha Baskaran, Ahmad Farhan Aznan, Attendance System Using a Mobile Device: Face Recognition, GPS or Both?. International Journal of Advances in Electronics and Computer Science, 2016; 26-32.

4. V. Somasundaram, M. Kannan and V. Sriram, Mobile based Attendance Management System, Indian Journal of Science and Technology. 2016; 9: 1-4.

5. Dhiman Sarker., Nafiez Ishtaique Hossian., Insan Arafat Jamil, Design and Implementation of Smart Attendance Management System Using Multiple Step Authentications. International workshop on computational intelligence, 2016; 91--95.

6. Jun lio, Attendance Management System using a Mobile Device and Web Application. International conference on network-based Information Systems, 2016; pp. 510--515.

7. R.Dinesh, S.R.Arun Provin, M.Aravindan, D.Rajeshwari. Library Access System Smart Phone Application using Android. International Journal of Computer Science and Mobile Computing. 2015; 4 : $142-149$.

8. YuXiang S, Cha Y.W, and Kim C.H. Comparison and Performance Analysis of App and Web-based One-stop Attendance Management. International Journal of e-Service Science and Technology. 2015; 8: $325-336$.

9. A.J.Kadam, Aradhana Singh, Komal Jagtap, Srujana Tankala. Mobile Web Based Android Application for College Management System. International Journal of Engineering and Computer Science.2017; 6: 20206-20209.

10. H. K. Nguyen, M. T. Chew. RFID-Based Attendance Management System. In: 2nd Workshop on Recent Trends in Telecommunications Research, 2017; pp. 1-6.

11. Manasi Kawathekar , An Android Application for Student Information System, International Journal of Advanced Research in Computer Engineering \& Technology, Volume 4 Issue 9, September 2015, ISSN: 2278 - 1323: pp. 3615--3619. 


\section{AUTHORS PROFILE}

Dr. Anil V Turukmane Associate Professor \& Head in Computer Science \& Engineering Department of Sharad Institute of Technology College of Engineering, Ichalkarnji, Kolhapur, Maharashtra, India. His research interests include network Security \& Cyber Security. He has published more than 15 papers in this field 